eISSN: 2659-6482

DOI: https://doi.org/10.14201/pmrt.23928

\title{
«LES CONTREPOINTISTES DE L'ÈCOLE D’ÉVORA». EL INTEGRALISMO LUSITANO Y LA ESCOLA DE ÉVORA EN EL NACIONALISMO MUSICAL DE LUÍS DE FREITAS BRANCO
}

\section{"Les contrepointistes de L'Ècole d'Évora». Lusitanian Integralism and the Escola d'Évora in Luis de Freitas Branco's Musical Nationalism}

\author{
Aarón PÉREZ BORRAJO \\ (Universidad de Salamanca) \\ aaronborrajo@usal.es
}

RESUMEN: El objetivo principal de este artículo consiste en identificar los mecanismos mediante los cuales el compositor y musicólogo Luís de Freitas Branco (1890-1955) diseña y configura un nacionalismo musical portugués sumamente particular a partir del marco teórico que le proporciona el Integralismo Lusitano. Movimiento protofascista activo en Portugal entre 1916 y 1933, de corte tradicionalista y monárquico, abogó por un proyecto cultural opuesto a la dimensión castellana y a las interferencias italianas que asolaron el panorama musical portugués durante el siglo XIX. Los agentes musicales integralistas entendieron que el contrapunto polifónico de los siglos XVI y XVII, asociado a la denominada Escola de Évora, debía ser el modelo a seguir para volver a situar a Portugal en la vanguardia europea del siglo XX. Para ello, en esta investigación se abordará el estudio de caso del capítulo «Les contrepointistes de l'École d'Evora», publicado en el tercer volumen de las Actes du Congrès d'Histoire de l'Art (1924). Testimonio de su participación en el congreso de título homónimo celebrado en París en 1921, esta fuente nos permitirá comprobar cómo el musicólogo portugués construye y difunde un imaginario musical nacional acorde a las doctrinas integralistas en un contexto internacional. 
Palabras clave: Música portuguesa; nacionalismo musical; música antigua; Escola de Évora; Integralismo Lusitano.

ABSTRACT: The main objective of this article is to identify the mechanisms by which the composer and musicologist Luís de Freitas Branco (1890-1955) designed and shaped a very particular Portuguese musical nationalism based on the theoretical framework provided by Integralismo Lusitano. A proto-fascist movement active in Portugal between 1916 and 1933, of a traditionalist and monarchical nature, it advocated a cultural project opposed to the Spanish dimension and the Italian interferences that devastated the Portuguese musical panorama during the 19th century. The integralist musical agents understood that the polyphonic counterpoint of the 16th and 17th centuries, associated with the so-called Escola de Évora, should be the model to follow in order to place Portugal once again in the European avant-garde of the 20th century. To this end, in this research he will address the case study of the chapter «Les contrepointistes de l'École d'Evora», published in the third volume of the Actes du Congrès d'Histoire de l'Art (1924). Testimony of his participation in the congress of the same name held in Paris in 1921, will allow us to see how the Portuguese musicologist constructs and spreads an imaginary national music according to the integralist doctrines in an international context.

Keywords: Portuguese music; music nationalism; early music; Escola de Évora; Integralismo Lusitano.

\section{LUÍS DE FREITAS BRANCO Y EL PROYECTO CULTURAL INTEGRALISTA}

Luís de Freitas Branco (1890-1955) puede ser considerado como una figura multifacética y sumamente poliédrica de gran relevancia en la escena musical y musicológica portuguesa durante la primera mitad del siglo XX. Compositor, crítico, musicólogo y profesor, su posicionamiento ideológico explícito y su dinamismo político fueron los responsables de la disminución progresiva de su peso en una vida pública estrechamente controlada por el Estado Novo (1933-1974). Su hijo João de Freitas Branco (1922-1989), matemático y musicólogo portugués, fue el principal valedor y dignificador de la figura de su padre tras su desaparición. A él le corresponde la autoría de algunas de las primeras aproximaciones al estudio de la producción musical y musicológica de Luís de Freitas Branco. 
AARÓN PÉREZ BORRAJO

«LES CONTREPOINTISTES DE L'ÈCOLE D'ÉVORA». EL INTEGRALISMO LUSITANO

Y LA ESCOLA DE ÉVORA EN EL NACIONALISMO MUSICAL DE LUÍS DE FREITAS BRANCO

Subdirector del Conservatório Nacional, en 1924 decidió abandonar su cargo para dedicar más tiempo y atención a su faceta compositiva. Freitas Branco antepuso la creación de una obra personal, su contribución particular a la historia de la música portuguesa, a una función administrativa aun cuando esta le proporcionaba un gran prestigio social. Máxima institución musical portuguesa, hasta su renuncia colaboró en la gestión de esta entidad bajo la dirección del eminente José Viana da Motta (1868-1948) ${ }^{1}$, figura a la que siempre profesó un gran respeto y admiración. Esta estima personal puede ser contrastada a partir de múltiples artículos en prensa y en publicaciones periódicas: «Viana da Mota de novo afirmou as prestigiosas qualidades que fazem dele um dos maiores pianistas de todos os tempos» (Branco, 1925: 2).

El magisterio musical de Freitas Branco en el Conservatório Nacional resultó fundamental para la generación de jóvenes compositores formados en este centro durante la segunda década del siglo XX. Sus enseñanzas tuvieron un especial impacto en el dominado «Grupo dos Quatro», compuesto por Jorge Croner de Vasconcelos (1910-1974), Armando José Fernandes (1906-1983), Pedro do Prado (1908-1990) y Fernando Lopes Graça (1906-1994)². Todos ellos consideraron a Freitas Branco como su modelo y maestro principal, entendiendo que era el compositor portugués más sobresaliente y con mayor proyección internacional durante este período histórico, y adaptando como propia la visión racionalista y científica con la que este autor abordaba el proceso compositivo (Silva y Latino, 2010a).

Finalmente, a pesar de toda la autoridad que Freitas Branco poseía, su posicionamiento político público lo acabó situando en el punto de mira del salazarismo, sin que su influencia en la vida musical portuguesa pudiera remediarlo. Asistimos, en definitiva, a la caída progresiva de un gigante intelectual en tres pasos. El primero de ellos es el proceso sancionador contra su persona y sin motivos aparentes que

1. José Viana da Motta (1868-1948) fue uno de los intérpretes portugueses más relevantes de finales del siglo XIX y principios del siglo XX. Virtuoso del piano y solista en numerosas giras internacionales, fue un firme defensor del wagnerianismo y de posiciones germanófilas opuestas a la hegemonía de las influencias italianas en Portugal durante el siglo XIX. Paralelamente a su labor como músico, ocupó el cargo de director del Conservatório Nacional hasta 1938, siendo relevado por el compositor Ivo Cruz.

2. Fernando Lopes Graça (1906-1994) fue uno de los compositores y musicólogos portugueses más relevantes del siglo XX. Alumno de Viana da Motta y de Freitas Branco en el Conservatório Nacional, su interés en la música popular portuguesa fue mayúsculo, fruto de la influencia de B. Bartók y M. de Falla. Preso político, integrante de movimientos antisalazaristas y autor de obras de alto contenido ideológico, finalmente se ubicó dentro de las tendencias neoclásicas, adaptándose a las nuevas fases artísticas de experimentación musical (Picoto y Cascudo, 2002). 
AARÓN PÉREZ BORRAJO

«LES CONTREPOINTISTES DE L'ĖCOLE D'ÉVORA». EL INTEGRALISMO LUSITANO

Y LA ESCOLA DE ÉVORA EN EL NACIONALISMO MUSICAL DE LUÍS DE FREITAS BRANCO

dirige el compositor portugués Ivo $\mathrm{Cruz}^{3}$ en 1939 en el Conservatório Nacional. Nuevo director de dicha institución, no solo había estado vinculado a la dimensión musical del Integralismo Lusitano, sino que había materializado gran parte del discurso musicológico nacionalista de Freitas Branco a partir de diversas actividades musicales programadas mediante el formato de «concerto histórico» ${ }^{4}$.

El segundo paso se produce en 1947 cuando, todavía apartado de sus responsabilidades laborales, esta situación se convierte en definitiva. Freitas Branco solicita una excedencia «voluntaria» mediante la cual cierra la puerta a cualquier posibilidad de regresar a su puesto como profesor en el Conservatório Nacional. Por último, el tercer paso supone su despido de la Emissora Nacional en 1951. La justificación empleada para ello es el incumplimiento del luto nacional impuesto tras la muerte del presidente de la República, el militar y político António Óscar de Fragoso Carmona (1869-1951) (Silva y Latino, 2010a). Sin embargo, a pesar de que este suceso pueda alcanzar casi la consideración de acción política antisalazarista, no existe ninguna información concreta al respecto.

La incorporación de Freitas Branco al Integralismo Lusitano, cuestión obviada y minusvalorada por una gran parte del colectivo musicológico, se convirtió en el inicio de una asociación de carácter bidireccional que condicionó la dirección que tomó su producción musicológica. Al mismo tiempo que nuestro autor generó una narrativa músico-nacional en sintonía con los dogmas integralistas, este se apoyó en el marco teórico e ideológico proporcionado por el Integralismo Lusitano para respaldar sus juicios nacionalistas y sus análisis musicales. Dicho movimiento político, con actividad entre 1916 y 1933, tuvo como objetivo el establecimiento

3. Ivo Cruz (1901-1985) fue un profesor, director de orquesta y compositor portugués. Formado bajo el magisterio de Ernesto Vieira (1848-1915) y de Tomás Borba, generó un corpus musical muy reducido e influenciado por el impresionismo francés, por temáticas nacionalistas y por la música antigua portuguesa. Su afinidad con el Integralismo Lusitano se fraguó durante sus estudios superiores en la Universidade de Lisboa (Silva y Latino, 2010b). En comparación con otros agentes musicales integralistas como Freitas Branco, su desempeño como compositor y director de orquesta provocó que su producción musicológica fuera sensiblemente menor. A nivel profesional, Ivo Cruz creó en 1931 la Sociedad Coral Duarte Lobo, alusión directa a la Escola de Évora. También desempeñó los cargos de director de la Orquestra de Câmara de Lisboa (1933), maestro de la Orquestra de Câmara de la Emissora Nacional (1934), y fue el fundador de la Orquestra Filarmónica de Lisboa (1937). A nivel institucional, ocupó el puesto de director de la Associação de Classe dos Músicos Portugueses (1932), y fue representante de los músicos en la Câmara Corporativa (1935), promoviendo la aplicación de políticas proteccionistas frente a los músicos extranjeros. Finalmente, en 1938 accedió a la dirección del Conservatório Nacional, la cual abandonaría en 1971. Su gestión fue sumamente polémica debido a su autoritarismo y a su desprecio por la música popular y por las nuevas vanguardias (Silva y Latino, 2010b).

4. Esta información puede ser contrastada en la siguiente fuente: Branco, L. de Freitas (1924a, February): Música. Concertos Históricos na Liga Naval. Diário de Notícias, p. 3. 
de una monarquía orgánica mediante un nacionalismo tradicionalista, ultraconservador y protofascista. Sin espacio dentro del sistema de partido único instaurado por Salazar en el Estado Novo, el Integralismo Lusitano estuvo integrado por intelectuales y académicos portugueses liderados por el poeta y ensayista António Sardinha (1888-1925).

Prueba de la vinculación de Freitas Branco con el Integralismo Lusitano es su capítulo «Música e instrumentos» (Branco, 1916), el cual forma parte del volumen A Questão Ibérica: Integralismo Lusitano, manifiesto fundacional del movimiento. Transcripción de la conferencia impartida en 1915 ante la sociedad lisbonense, su participación en este evento le posicionó como una referencia musicológica fundamental para el Integralismo Lusitano, respaldado por todo un discurso nacionalista difundido en prensa y en publicaciones periódicas. En este capítulo, el musicólogo portugués afirmó la existencia de una tradición histórico-musical nacional de gran valor en la que es posible encontrar fórmulas musicales portuguesas ajenas al hacer europeo.

Para identificar estos mecanismos identitarios, Freitas Branco tomó como modelo los parámetros estereotipados y emocionales que António Sardinha asignó a Portugal en su capítulo «O território e a raça»: lirismo, idealismo, sentimentalismo, etc. (Sardinha, 1916). Nuestro autor pretendió demostrar la existencia de una dimensión musical portuguesa propia y autónoma desde la independencia de España en 1640, hito político pertinente a la hora de contrastarlo con la desnacionalización musical acaecida durante el siglo XIX. En definitiva, Freitas Branco se apoyó en las consignas ideológicas integralistas a la hora de configurar una nueva visión sobre la historia de la música en Portugal (Pina, 2016).

Con base en todo lo anterior, resulta evidente que, si los integralistas anhelaban el regreso y la reinstauración de las estructuras de poder del pasado, sus agentes musicales caminarían en la misma dirección: la adecuación entre discursos fue total. El proyecto cultural del Integralismo Lusitano se construyó a partir de un concepto de tradición estanco, inalterable y atemporal. Su utilización sistemática justificaba y legitimaba la decisión de convertir un pasado lejano en la máxima representación de la modernidad contemporánea lusa. Es decir, consideraron que el contrapunto polifónico portugués era el mejor ejemplo para mostrar cómo ejercer musicalmente una «verdadera idiosincrasia» nacional en un contexto internacional y contemporáneo.

Los integralistas propusieron el rescate y la recuperación de un pasado musical $\mathrm{y}$ cultural cercenado por las distorsiones e injerencias musicales italianas acontecidas durante el siglo XIX. Entendieron que los siglos XVI y XVII constituyeron un período artístico autónomo y soberano, libre de influencias extranjeras, y, por lo tanto, sumamente pertinente a la hora de reivindicar un arte propiamente nacional en su tiempo presente. Definitivamente, existió una correspondencia entre 
AARÓN PÉREZ BORRAJO

«LES CONTREPOINTISTES DE L'ÈCOLE D'ÉVORA». EL INTEGRALISMO LUSITANO

Y LA ESCOLA DE ÉVORA EN EL NACIONALISMO MUSICAL DE LUÍS DE FREITAS BRANCO

la narrativa sociopolítica y cultural del Integralismo Lusitano, dentro de la cual se integraba el ámbito musical y musicológico. Ambas dimensiones estuvieron basadas en la invención de relatos, en las distorsiones históricas, en la presencia de interferencias e interrupciones externas en un desarrollo nacional decimonónico, y en la reconstrucción idealizada de determinados períodos históricos que respondían a unos intereses ideológicos específicos durante las primeras décadas del siglo XX.

Los agentes musicales del Integralismo Lusitano -entre los cuales sobresalen Luís de Freitas Branco, Ivo Cruz y Mário de Sampaio Ribeiro- $-^{5}$ consideraron que la Escola de Évora debía ser el modelo a imitar para volver a ser musicalmente portugueses en el siglo XX. Esta dispuso de un lugar privilegiado en la cronología y en la historia de la música portuguesa diseñada por Freitas Branco en $A$ música em Portugal (Branco, 1929). Ubicada entre la época del estilo vocal acompañado y la del bajo cifrado, su contrapunto polifónico respondió a los parámetros vigentes en la época del estilo a capella (Cascudo, 2010).

A pesar de que no contamos con demasiada información sobre este período musical, sabemos que el denominado estilo a capella se correspondió con la música polifónica portuguesa compuesta durante los siglos XVI y XVII. Las figuras más relevantes de esta etapa, caso de Manoel Mendes (1547-1605) y de Duarte Lobo (1564?-1646), formaron parte de la Escola de Évora. Freitas Branco afirmó que, probablemente, este último fue uno de los personajes de mayor trascendencia en la música portuguesa. Para respaldar esta aseveración nos encontramos con alusiones al empleo de la forma cíclica por parte de Lobo, definida como una verdadera innovación artística. En este sentido, el musicólogo portugués se encargaría de recuperar, reconfigurar y reutilizar este formato musical en la composición de su Sinfonia n. 2 (1926) (Cascudo, 2010). Mediante estrategias

5. Mário de Sampaio Ribeiro (1898-1966) fue un musicólogo, crítico y pedagogo musical portugués. Educado en el Conservatório Nacional, adquirió su formación musicológica de manera autodidacta. Participó activamente en la escena cultural del Estado Novo, aunque también desempeñó cargos institucionales como el de jefe de Sección en la Direç̧ão-Geral da Contabilidade Pública (Nery, 2010). Sampaio Ribeiro fue inspector de Canto Coral da Mocidade Portugnesa, presidente del Sindicato Nacional dos Músicos y procurador en la Câmara Corporativa. En 1941 fundó el coro Polyphonia-Schola Cantorum dedicado a la programación de música antigua portuguesa. Orientó su labor musicológica al estudio de los compositores y de las escuelas portuguesas más relevantes entre los siglos XVI y XVIII, con un especial interés en la figura del rey João IV. Sampaio Ribeiro fue pionero en la edición de fuentes musicales portuguesas de los siglos XVI y XVII, así como en la traducción y edición crítica de libretos pertenecientes al repertorio operístico europeo (Nery, 2010). Toda su producción musicológica estuvo influenciada por sus convicciones nacionalistas y por su cercanía ideológica con el Integralismo Lusitano. Exaltó desmedidamente la calidad de las prácticas musicales nacionales frente a las dinámicas artísticas internacionales, considerando que el contrapunto polifónico de la Escola de Évora debía ser la referencia principal para la creación de una identidad musical nacional. 
musicales y musicológicas de esta índole fue capaz de justificar la noción de modernidad que asignó arbitrariamente a la Escola de Évora y a sus integrantes.

Desde el punto de vista de los agentes musicales integralistas, el impacto de Duarte Lobo en el desarrollo musical portugués se vio difuminado y ensombrecido por las dinámicas italianas dominantes durante el siglo XIX. Ante esta situación, trataron de reivindicar y de poner de manifiesto la vigencia de los procedimientos compositivos empleados por los integrantes de la Escola de Évora, construyendo tales argumentaciones a partir de la utilización sistemática de un concepto de tradición estático, permanente e inalterable. Este colectivo se convirtió, por lo tanto, en la máxima representación de la modernidad, originalidad y autenticidad musical portuguesa. No obstante, debemos tener en cuenta que dichas sentencias y aseveraciones, sustentadas por frágiles juicios estéticos, contribuyeron a la creación de distorsiones y confusiones históricas, hecho que T. Cascudo (2004: 323) sintetiza certeramente: «Bajo la luz nacionalista el defecto [...] es una cualidad congénita de la raza y tal vez aquella que más la individualiza».

\section{CONTEXTUALIZACIÓN DE «LES CONTREPOINTISTES DE L'ÉCOLE D’ÉVORA»}

El capítulo «Les Contrepointistes de l'École d'Évora»(Branco, 1924c), integrado en el tercer volumen de Actes du Congrès d'Histoire de l'Art (1924), supone el estudio de caso a partir del cual se articula esta investigación. Esta fuente, una nueva exaltación nacionalista del contrapunto polifónico portugués, propone una introducción al estudio histórico-musical de la Escola de Évora. En consonancia con un posicionamiento musicológico claramente ideologizado, nuestro autor pretende establecer conexiones entre los procesos musicales característicos de este colectivo y las prácticas habituales en Europa durante la época palestriniana. Su objetivo final no es otro que situar a Portugal dentro de un escenario musical europeo jerarquizado y con un discurso aparentemente homogéneo.

Para ello, el musicólogo portugués nos traslada al siglo XVI con el propósito de mostrarnos el nacimiento, el desarrollo y la decadencia de la Escola de Evora. En este sentido, opta por emplear un modelo histórico orgánico, el cual le permite la configuración de un discurso perfectamente coordinado con su lectura nacionalista. A través de esta fuente, el autor orienta sus esfuerzos hacia un público internacional altamente cualificado. Esta afirmación se encuentra respaldada por el prestigio y el elitismo intelectual del contexto académico en el que presenta esta aportación.

Freitas Branco se sirve de la Escola de Évora para participar en 1921 en el Congrès d'Histoire de l'Art organizado por la Société de l'Histoire de l'Art Français. 
Todas las ponencias presentadas en este evento, celebrado en París entre el 6 de septiembre y el 5 de octubre, fueron publicadas en cuatro volúmenes de actas en 1924 por Les Presses Universitaires de France, acompañadas de un prefacio del historiador André Michel (1853-1925). Subdirector del Conservatório Nacional durante este período, la aportación de nuestro autor forma parte del tercer volumen, dedicado a las investigaciones presentadas en la segunda y en la cuarta sección del congreso. En esta fuente se reúnen diversas contribuciones pertenecientes a ámbitos como la escultura, las artes decorativas, la historia de la música, o las relaciones existentes entre las escuelas artísticas nacionales europeas y la francesa.

En la cuarta sección, dedicada exclusivamente a la historia de la música, Freitas Branco se encuentra acompañado por figuras sumamente relevantes dentro de la musicología europea. Este es el caso de investigadores como: Felipe Pedrell (1841-1922)6 musicólogo catalán e ideólogo del nacionalismo musical español; Eduard Bernoulli (1867-1927), profesor en la Universidad de Zúrich; Luigi Torri (1863-1932), director de la Biblioteca Nacional Universitaria de Turín; Charles Van den Borren (1874-1966), director de la Biblioteca del Conservatorio de Música de Bruselas; Karl Nef (1873-1935), profesor en la Universidad de Bâle; Felice Boghen (1869-1945), profesor en el Conservatorio de Música de Florencia; Henry Prunières (1886-1942), director de la Revue Musicale; Edward Burlingame Hill (1872-1960), profesor en la Universidad de Harvard; Gustave Soulier (1872-1937), director del Instituto Francés de Florencia; etc.

Freitas Branco inicia su capítulo proporcionando al lector un extenso listado de compositores portugueses adscritos a los siglos XVI y XVII. A partir de este conjunto de artistas - casi ochenta ejemplos distribuidos en base a criterios cronológicos y alfabéticos- el musicólogo justifica la pertinencia de su estudio sobre el contrapunto polifónico portugués, aprovechando para exponer los pilares sobre los cuales construye sus teorías nacionalistas. Mediante este conjunto de datos pretendidamente inéditos, el autor pretende dejar al lector abrumado y sin capacidad de réplica. El hecho de que apueste por una ordenación alfabética le permite exhibir una suerte de objetivismo científico que, aparentemente, le impide caer en favoritismos. Nuevamente es destacable la presencia del rey João $\mathrm{IV}^{7}$, quien,

6. Freitas Branco fue un gran conocedor de la labor musicológica y nacionalista desarrollada por Felipe Pedrell. Ejemplo de ello puede ser la admiración que profesó por la dignificación de la escuela de vihuelistas españoles que este último llevó a cabo junto a Rafael Mitjana (1869-1921). Al respecto, puede ser de interés la siguiente fuente: Branco, L. de Freitas (1924b, September). Guitarristas Portuguezes. Música: Revista das Artes, n. ${ }^{\circ}$ 2, 55-57.

7. João IV (1604-1656), O Restaurador, también conocido por el sobrenombre de Rei Músico, fue un rey portugués perteneciente a la Casa de Bragança. Compositor e intérprete notable, fue el propietario de una de las bibliotecas musicales más importantes de Europa, la cual desapareció en 1755 debido al terremoto de Lisboa. Según Howel y Nery (2002), este monarca 
representante único y absoluto de Portugal, encarna la idea de consenso nacional incluso en la dimensión artística y musical.

Con un énfasis específico en la Escola de Évora, Freitas Branco ambiciona dar a conocer la actividad contrapuntística portuguesa en un contexto internacional. Paralelamente, demanda un reconocimiento externo a la importancia artística e histórica de Portugal durante este período, como si de una suerte de reparación nacional se tratase. Al respecto, el musicólogo portugués se pronuncia de la siguiente forma: «Je citerai, cependant, les principaux noms, non seulement pour donner une idée de la richesse de notre production musicale à l'époque palestrinienne, mais encore, et surtout, parce qu'ils sont, pour la plupart, complètement inconnus hors du Portugal» (Branco, 1924c: 846). Nos situamos, en definitiva, ante una acción que adquiere connotaciones casi diplomáticas.

A pesar de que el renacimiento musical portugués fue una época que careció de interés para una gran parte de la musicología portuguesa, a excepción de casos específicos, nuestro autor consideró que la amplia producción musical de estos siglos le permitía corroborar: «[...] la splendeur d'une période, âge d'or de la musique portugaise [...]» (Branco, 1924c: 847). El riesgo que corre Freitas Branco al realizar tales afirmaciones, las cuales ni siquiera son respaldadas por el colectivo en el que él mismo se integra, es evidente. Se sitúa exactamente en la misma posición dogmática, carente de referencias documentales y sostenida por frágiles juicios estéticos que reprueba y reprocha al reflexionar sobre la influencia del wagnerianismo en Portugal: «É inconcevibel a suggestão exercida pelos prophetas e como lhes acceitam irreflextidamente as doutrinas» (Branco, 1915: 186).

Por otro lado, el límite de extensión impuesto desde el ámbito editorial le impide emprender un análisis exhaustivo de la Escola de Évora. Sin embargo, su posicionamiento ideológico nacionalista y su motivación propagandística le impulsan a transformar estas restricciones iniciales en una magnificación manifiesta y directa del contrapunto polifónico portugués: «Je dois, à mon grand regret, renoncer à m'occuper ici de plusieurs musiciens remarquables [...]» (Branco, 1924c: 847). Freitas Branco pone todo su empeño en evitar que la selección de seis estudios de caso que propone sea traducida como un reconocimiento implícito sobre la escasa calidad del corpus musical del resto de compositores en activo durante este período.

desarrolló una intensa labor como mecenas de una serie de compositores portugueses que, casualmente, conforman lo que desde el Integralismo Lusitano se denominó Escola de Évora. 
AARÓN PÉREZ BORRAJO

«LES CONTREPOINTISTES DE L'ĖCOLE D'ÉVORA». EL INTEGRALISMO LUSITANO

Y LA ESCOLA DE ÉVORA EN EL NACIONALISMO MUSICAL DE LUÍS DE FREITAS BRANCO

\section{3. «LES CONTREPOINTISTES DE L'ÉCOLE D’ÉVORA»: ¿CONTINUIDAD ARTÍSTICA A LO LARGO DE DOS SIGLOS?}

A lo largo de este capítulo, Freitas Branco profundiza en el análisis de seis compositores, los cuales no solo pertenecen a la Escola de Évora, sino que también posibilitan la realización de un recorrido histórico a través de sus diferentes fases y etapas. Los seis artistas por los que el musicólogo luso se decanta son los siguientes: Manoel Mendes, Duarte Lobo, Manoel Cardoso (1566-1650), Filipe de Magalhães (1571-1652), João Lourenço Rebello (1610-1661)8 y Diego Dias de Melgaço (16381700). Indudablemente, esta selección arbitraria se encuentra estrechamente ligada a la relevancia del modelo histórico orgánico mencionado anteriormente. A través de este, teniendo en cuenta la ubicación cronológica de cada compositor, Freitas Branco asigna papeles y roles específicos en el desarrollo musical de este movimiento.

Tras definir su objeto de estudio, el autor destaca la autonomía y la independencia de la Escola de Évora respecto a otras corrientes artísticas internacionales, incidiendo de este modo en su especificidad nacional. Esta lectura musical autárquica y emancipada es la que le permite realizar un discurso de corte nacionalista, demandando un lugar para Portugal en la vanguardia musical renacentista europea. Para ello, el primer paso consiste en refutar todas las hipótesis que apuntan a que la práctica del contrapunto polifónico en Évora fue iniciada por el flamenco Rinaut de Melle9, maestro de capilla del cardenal-rey D. Henrique ${ }^{10}$. Desde un punto estrictamente musicológico, los argumentos de Freitas Branco resultan insuficientes ante la ausencia de información y de referencias documentales que corroboren aseveraciones tan imprecisas como la de que Manoel Mendes, supuesto fundador de este movimiento, ya componía activamente antes de la presencia de Melle en Évora.

En este sentido, el musicólogo portugués cercena cualquier intento de desarrollo argumental al omitir tanto la fecha de la llegada de Melle a Portugal como la datación de la producción contrapuntística de Mendes. Convenientemente, afirma lo siguiente sobre esta última cuestión: «Aucune de ses compositions, qui se font remarquer par la merveilleuse pureté de leur écriture, n’a été imprimée» (Branco,

8. Este compositor portugués también puede ser identificado por el nombre de João Soares Rebello.

9. Rinaut de Melle (1544-1598) fue un compositor flamenco profundamente influenciado por el estilo de Giovanni Pierluigi da Palestrina (1525-1594). Formado musicalmente en la catedral de Saint Rombaut (Mechelen, Bélgica), desarrolló su carrera musical como maestro de capilla en la corte real de Lisboa (Myers, 2002). Finalmente, se estableció en Italia tras la anexión de Portugal a España en 1580 bajo el reinado de Felipe II de la Casa de Austria.

10. Henrique I de Portugal (1512-1580), también conocido como el Cardenal-Rey, fue el último monarca portugués perteneciente a la Casa de Avís. Cardenal y arzobispo emérito, tuvo que suceder en el trono a su sobrino Sebastião I tras su muerte en la batalla de Alcazarquivir. 
1924c: 848). Freitas Branco pone todo su empeño en evitar que se atribuya el mérito de la constitución de la Escola de Évora a un agente musical no nacional. Este hecho desmontaría por completo su proyecto musicológico nacionalista, desestabilizando incluso su visión global sobre la historia de la música portuguesa. El autor únicamente pretende ratificar sus tesis nacionalistas, exhibiendo un nulo interés por profundizar en un campo de estudio ineludible: el comienzo de la actividad musical de la Escola de Évora.

Si la figura de Manoel Mendes marca el comienzo de este colectivo, la de Duarte Lobo representa su período de mayor esplendor. Por ello, Freitas Branco no duda en equipararlo y en compararlo con los compositores europeos más importantes de este período: «Le plus grand de tous, célébré par les théoriciens espagnols de son temps à l'égal de Tomas de Victoria et de Mathias Romero, fut Duarte Lobo, Eduardus Lupus, le Palestrina portugais [...]» (Branco, 1924c: 848). El autor exhibe un sentimiento de amargura, incluso de afrenta nacional, al desconocer los motivos por los que la producción musical de Lobo, a diferencia de otros artistas contemporáneos, no ha sido rescatada y tenida en cuenta por la musicología europea: «La vie du plus grand compositeur portugais, de l'un des plus éminents de la période palestrinienne, se passa, modeste et sans bruit, comme celle de tous les maîtres de chapelle de son temps» (Branco, 1924c: 849).

Sin embargo, a pesar de la relevancia per se del talento artístico de Lobo, lo fundamental es conectar su actividad compositiva con el magisterio de Mendes. De este modo, Freitas Branco es capaz de demostrar la existencia de un modelo orgánico, el cual se basa en una suerte de continuidad histórico-musical depurada y estilizada a lo largo de dos siglos. No obstante, paralelamente a la exaltación nacionalista y patriótica de Duarte Lobo, el autor también lleva a cabo un ejercicio de autocrítica. Bajo su punto de vista, es responsabilidad de la musicología portuguesa rescatar y difundir la producción de los compositores nacionales en un contexto internacional. Freitas Branco entiende que la ausencia de un discurso musicológico nacionalista sólido y coordinado es la principal responsable de que la posición de Portugal en la historia de la música europea sea diferente a la de países como España. En este sentido, la autopropaganda que realiza sobre su propio trabajo no pasa desapercibida.

El tercer estudio de caso recae sobre la figura de Manoel Cardoso, alumno de Mendes y eminente compositor de misas basadas en motivos populares. El musicólogo portugués se sirve de él para transformar un evento histórico en un motivo de enorgullecimiento nacional: «La réputation de Manoel Cardoso était telle, que, voyageant en Espagne, le roi Philippe lui fit un accueil honorable qui rappelle l'anecdote du grand Frédéric et de Jean-Sébastien Bach» (Branco, 1924c: 850). Una vez más, el autor se ampara bajo la autoridad y el poder de un agente no nacional de gran impacto histórico para obtener una legitimidad musical y 
AARÓN PÉREZ BORRAJO

«LES CONTREPOINTISTES DE L'ÈCOLE D'ÉVORA». EL INTEGRALISMO LUSITANO

Y LA ESCOLA DE ÉVORA EN EL NACIONALISMO MUSICAL DE LUÍS DE FREITAS BRANCO

artística. Semeja que Portugal es incapaz de constituirse internacionalmente por sí misma, precisando la aprobación y el respaldo de aquellos de quienes se intenta distanciar culturalmente: la Casa de Austria, rama española de la dinastía Habsburgo, presente en este país entre 1580 y 1640.

Tras Manoel Cardoso, de acuerdo con el modelo orgánico del musicólogo portugués, comienza el declive de la Escola de Évora. Este nuevo período se encuentra personificado por los no menos válidos Filipe de Magalhães, João Lourenço Rebello y Diego Dias de Melgaço. Llegados a este punto, el interés de Freitas Branco en ubicar y en localizar geográficamente a los compositores que conforman este movimiento adquiere su verdadero significado. El hecho de que Magalhães y Lourenço Rebello nacieran fuera de la región y del área metropolitana de Évora le permite ratificar su concepción de esta como centro neurálgico de la práctica del contrapunto polifónico en Portugal. Desde su punto de vista, por lo tanto, analizar la Escola de Évora equivale a profundizar en el estudio de una escuela musical nacional portuguesa. Por otro lado, también resulta significativa la mención a las aportaciones musicológicas de Tomás Borba $^{11}$ sobre Filipe de Magalhães. Esta cuestión demuestra cómo Freitas Branco percibe en la calculada alusión y citación de agentes culturales afines a su figura un medio para reforzar su posición no solo en el exterior, sino también ante la musicología portuguesa.

João Lourenço Rebello, quinto estudio de caso, podría responder al interés del autor en introducir al rey João IV dentro de su discurso musical nacionalista. Compañero de estudios del monarca, el favor real le permitió acceder a cargos musicales de prestigio. Sorprendentemente, Freitas Branco se aferra a una cuestión tan irrelevante como su composición de una misa por la muerte de Luis XIII de Francia (1601-1643), le Juste, para justificar parcialmente su participación en este evento. Es decir, emplea esta pieza musical para probar la existencia de una relación -de naturaleza diplomática, no artística- entre la Escola de Évora y Francia. A pesar de ser un aspecto aparentemente irrelevante dentro de la dimensión global de su intervención, satisfacer este interés de los organizadores del Congrès d'Histoire de l'Art le permite difundir internacionalmente todo un imaginario musical adecuado a la doctrina y al proyecto cultural del Integralismo Lusitano.

Finalmente, sobre Diego Dias de Melgaço, sexto y último estudio de caso, Freitas Branco afirma lo siguiente: «[...] maintint jusqu’à sa mort la splendeur

11. Tomás Borba (1867-1950) fue un musicólogo portugués que desarrolló una intensa actividad como profesor de armonía en el Conservatório Nacional. Ordenado sacerdote, ocupó cargos institucionales durante la Primera República portuguesa (1910-1926). Bajo su magisterio estuvieron algunas de las figuras musicales portuguesas más importantes de la primera mitad del siglo XX como Luís de Freitas Branco, Pedro de Freitas Branco (1896-1963) o Rui Coelho (1889-1986). 
musicale de l'église métropolitaine d'Evora. Il écrivit beaucoup, et il existe, en manuscrit, une quantité d'ouvrages de Melgaço qui conservent toute la pureté de style de ses maîtres et modèles» (Branco, 1924c: 850). Pese a no haber disfrutado del magisterio de Manoel Mendes, fallecido treinta y tres años antes de su nacimiento, el autor se esfuerza en crear una suerte de continuidad artística entre el primer y el último exponente de la Escola de Évora. Para ello, afirma la existencia de una serie de parámetros musicales supuestamente compartidos por este conjunto de compositores, los cuales no desarrolla en ningún momento. Más allá del desarrollo individual de cada artista, son estos rasgos compartidos los que le permiten referirse a la Escola de Évora como a una entidad uniforme y cohesionada durante los siglos XVI y XVII.

Sin lugar a duda, plantear la existencia de una pluralidad procedimental dentro de este movimiento podría resultar perjudicial para la consolidación de la lectura nacionalista que propone el musicólogo portugués. Este hecho equivaldría a referirse a una identidad musical polisémica en la que todas las opciones son igualmente válidas al estar amparadas por la Escola de Évora. Dicho escenario contradeciría el concepto de tradición estable e inalterable que rige tanto el nacionalismo musical de Freitas Branco como el proyecto cultural del Integralismo Lusitano. Esta tendencia unidireccional y exclusiva no solo se aplica en un escenario interno, sino que todos estos juicios personales y subjetivos de carácter estético también sirven para diferenciar a la Escola de Évora de otras corrientes musicales europeas: «[...] ils se montrent, en général, plus amis de l'expression, et, notamment, de la dissonance comme moyen d'expression, que d'autres musiciens du même style» (Branco, 1924c: 851).

\section{CONCLUSIONES}

A lo largo de esta investigación, se ha pretendido demostrar la afinidad existente entre Luís de Freitas Branco y el Integralismo Lusitano. Esta relación, de carácter bidireccional, se puede confirmar a partir de la similitud entre discursos y lecturas nacionales, tal y como revela el capítulo «Les contrepointistes de l'École d'Évora». Al mismo tiempo que este movimiento sociopolítico de corte protofascista le proporciona una plataforma teórica e ideológica sobre la cual asentarse, Freitas Branco contribuye a la configuración de una historia musical y de un proyecto cultural adecuado al Integralismo Lusitano. A través de un lenguaje y de unas herramientas teórico-conceptuales comunes y compartidas, el autor profundiza en el análisis de escuelas y colectivos musicales cuidadosamente seleccionados: caso de la Escola de Évora. Sin embargo, la relevancia de su actividad musicológica también está motivada por sus esfuerzos en difundir internacionalmente la reivindicación de un pasado musical concreto. 
Respecto a la fuente seleccionada, resulta evidente que tras «Les contrepointistes de l’École d'Évora» se encuentra una intensa motivación nacionalista que Freitas Branco se encarga de exponer del siguiente modo: «[...] nous ne sommes pas seulement un peuple de navigateurs et de conquérants, mais que, comme M. de Figueiredo l'a déjà démontré, en étudiant l'école du génial Nuno Gonçalves en peinture, nous possédons de glorieuses traditions artistiques, même en musique» (Branco, 1924c: 852). Este fragmento revela que el musicólogo portugués no solo asume y perpetúa esta clase de estereotipos nacionales e identitarios, creados e impuestos habitualmente desde el exterior, sino que también muestra su legítima pretensión de trascenderlos a partir del arte. Este objetivo final justifica la realización de una lectura distorsionada de la música portuguesa a partir de un método histórico carente de herramientas musicológicas.

Principalmente, el interés de este estudio de caso responde a su difusión exterior, pero también a la formación intelectual y a la verdadera agencia musical y musicológica del público al que Freitas Branco se dirige. En este sentido, «Les contrepointistes de l'École d'Evora» podría funcionar como un elemento seudodiplomático, el cual se sirve de la platea internacional habilitada tanto por el congreso como por la posterior edición de actas. Freitas Branco aprovecha esta oportunidad para introducir su discurso en una nueva dimensión ajena a las -bajo su propio criterio- limitaciones de la musicología portuguesa, para ser legitimado mediante la aprobación y la aceptación de autoridades extranacionales, e incluso para establecer paralelismos y semejanzas con otras escuelas nacionales europeas. La historia de la música portuguesa, en definitiva, se sitúa en un primer plano.

\section{BIBLIOGRAFÍA}

Branco, L. de Freitas (1915). Philosophia wagneriana. A Arte Musical, n. ${ }^{\circ} 406,185-187$. Branco, L. de Freitas (1916). Música e instrumentos. En A Questão Ibérica: Integralismo Lusitano (pp. 119-143). Lisboa: Almeida Miranda \& Sousa.

Branco, L. de Freitas (1924a, febrero). Música. Concertos Históricos na Liga Naval. Diário de Notícias, p. 3.

Branco, L. de Freitas (1924b). Guitarristas Portuguezes. Música: Revista das Artes, n. 2, 55-57.

Branco, L. de Freitas (1924c). Les contrepointistes de l'école d'Évora. En Actes du Congrès d'Histoire de l'Art (pp. 846-852). Paris: Les Presses Universitaires de France.

Branco, L. de Freitas (1925, febrero). S. Luís. Diário de Lisboa, p. 2.

Branco, L. de Freitas (1929). A música em Portugal. Lisboa: Imprensa Nacional.

Cascudo, T. (2004). Por amor do que é portugués: el nacionalismo integralista y el renacimiento de la música antigua entre 1924 y 1934. En Concierto barroco: estudios sobre música, dramaturgia e historia cultural (pp. 309-330). Logroño: Universidad de La Rioja. 
Cascudo, T. (2010). Historiografía y composiciones en Portugal en el período de entreguerras: dos casos de estudio. En Cruces de caminos: intercambios musicales y artísticos en la Europa de la primera mitad del siglo XX (pp. 299-318). Granada: Editorial Universidad de Granada.

Howell, A. y Nery, R. Vieira (2002). João IV, King of Portugal. En The New Grove of Music and Musicians (vol. 13, pp. 128-129). London: MacMillan Publishers.

Myers, P. A. (2002). Mel [Melle], Rinaldo de [Raynaldus, Renatus, René, Renerus]. En The New Grove of Music and Musicians (vol. 16, pp. 302-303). London: MacMillan Publishers.

Nery, R. Vieira (2010). Ribeiro, Mário Luís de Sampaio. En Enciclopédia da Música em Portugal no Século $X X$ (vol. 4, pp. 1121-1123). [Lisboa]: Temas e Debates-Círculo de Leitores.

Picoto, J. C. y Cascudo, T. (2002). Graça, Fernando Lopes. En The New Grove Dictionary of Music and Musicians (vol. 10, pp. 243-245). London: MacMillan Publishers.

Pina, M. I. A. da Silva (2016). Neoclassicismo, nacionalismo e latinidade em Luís de Freitas Branco, entre as décadas de 1910 e 1930. (Dissertação de Mestrado. Universidade Nova de Lisboa).

Sardinha, A. (1916). O território e a raça. En A Questão Ibérica: Integralismo Lusitano (pp. 9-76). Lisboa: Almeida Miranda \& Sousa.

Silva, M. D. y Latino, A. (2010a). Branco, Luís Maria da Costa de Freitas. En Enciclopédia da Música em Portugal no Século XX (vol. 1, pp. 158-165). [Lisboa]: Temas e Debates-Círculo de Leitores.

Silva, M. D. y Latino, A. (2010b). Cruz, Ivo. En Enciclopédia da Música em Portugal no Século $X X$ (vol. 2, pp. 350-352). [Lisboa]: Temas e Debates-Círculo de Leitores.

VV. AA. (1916). A Questão Ibérica: Integralismo Lusitano. Lisboa: Almeida Miranda \& Sousa.

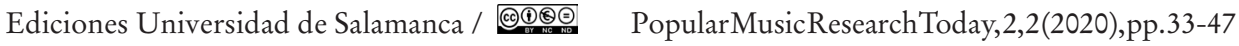


